\title{
Effect of FinInclinationson Natural Convection Heat Transfer by using CFD
}

\author{
Sk. Farooq \\ Assistant Professor, Department of Mechanical Engineering, \\ VFSTR University, Guntur-522213, Andhra Pradesh, India \\ Author E-mail: farooq.314@gmail.com
}

\begin{abstract}
The natural convection heat transfer process is commonly used in cooling of various electric, electronic, engines and it can be enhanced by use of fins attaching to its surfaces. The convective heat transfer coefficient of the finned surface not only depends on height, thickness, temperature difference and material but also on the inclination of fins to its base surface. This work presents the variation of convective heat transfer coefficient and the base temperature of fins by positioning the fins at various angle of inclinations ranging from $35^{\circ}$ to $90^{\circ}$ to its base surface, and varying the thickness and height of fins by using Ansys16.0 Icepack tool. The results shows the considerable variation in heat transfer coefficients and base temperature of fins by varying inclination angles, height and thickness of fins.
\end{abstract}

Key words: Natural convection, Inclination angle, heat transfer coefficient, base temperature of fin.

\section{INTRODUCTION}

Finned surfaces are extensively used in cooling of electronic devices, aircraft engines, automobile engines, refrigerators etc. Natural convection occurs if this motion and mixing is caused by density variations resulting from temperature differences within the fluid. Large number of experimental and numerical works has been carried out to study the effect of fin parameters like fin height, fin spacing etc. on heat transfer rate from fin array by the researchers. H. Yuncu, G. Anbar [1] done experimental on rectangular fins on a horizontal base in free convection heat transfer and varied the fin height and spacing for 15 sets of fin arrays and found that for a given base-to-ambient temperature difference the convection heat transfer rate from fin-arrays takes on a maximum value as a function of fin spacing and fin height.

Ilker Tari, Mehdi Mehrtash [2] has studied using correlations plate-fin heat sinks in both horizontal and slightly inclined of the base plate from horizontal orientationsto the inclination angles of $\pm 60^{\circ}, \pm 75^{\circ},+80^{\circ}, \pm 85^{\circ}, \pm 90^{\circ}$ from the vertical.

S. V. Naidu et al.[3] has studied experimentally and theoretically to determine the effect of inclination of the base of the fin array on heat transfer rate and found a good agreement for different inclinations like $0^{\circ}, 30^{\circ}, 45^{\circ}$, $60^{\circ}$, and $90^{\circ} \cdot \mathrm{S}$. V. Kadbhane and D. D. Palande[4] experimentally studied the heat transfer from vertical rectangular fin array with isothermal and constant heat flux conditions and found that convective heat transfer rates decreases by varying the angle from $0^{\circ}$ to $90^{\circ}$.

Welling and Wooldridge [5] investigated that free convection heat transfer from rectangular fins placed on a vertical plate. They observed that there is an optimum fin height for maximum heat transfer for a particular fin spacing.

Literature survey indicates that only the base plate was made to incline at different angles and orientations where fins are placed normal to the surface of the base plate. Now in the present work the base plate is made to be placed in horizontal and vertical position where as fin surfaces aremade to be inclined $(\theta)$ to the base plate surface by varying the angle from $35^{\circ}$ to $90^{\circ}$. The heat transfer coefficient and base temperature of fin is found to vary with orientations, inclinations, thickness and height of fins.

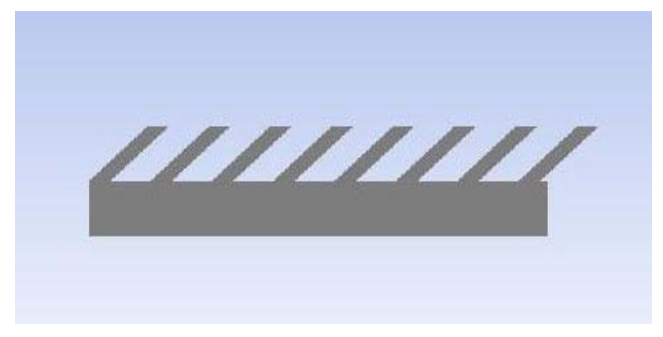

(a) $\quad \theta=35$

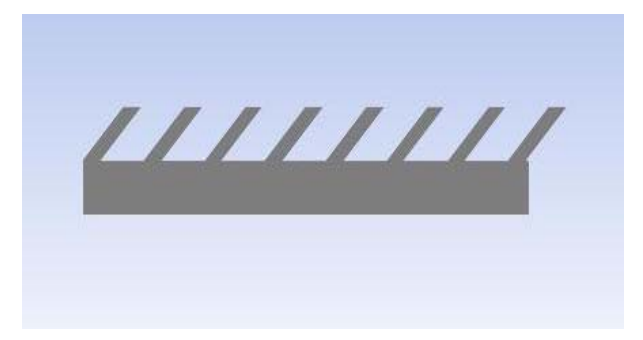

(b) $\quad \theta=45$ 


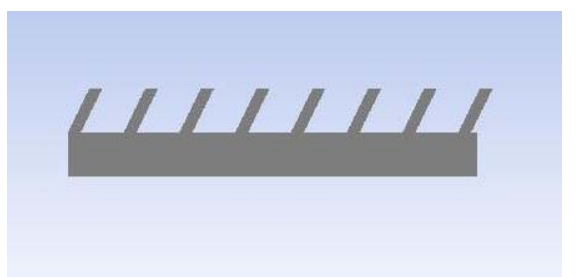

(c) $\quad \theta=60$

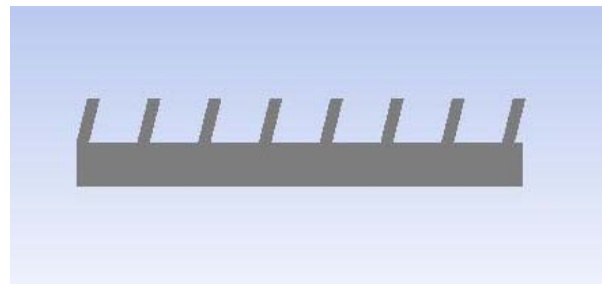

(d) $\quad \theta=70$

Fig.1. Models of inclined fins heat sinks at different angles

\section{MATHEMATICAL MODELING}

Fig. 1 shows geometrical models of plate finned surfaces inclined to its rectangular base surface by varying the angle from $35^{\circ}$ to $90^{\circ}$ where ' $\theta$ ' is the angle of inclination of fin surface in horizontal and vertical orientation. The sink base and fins are made of aluminum material, dimensions of sink base are $100 \mathrm{~mm}$ in width $110 \mathrm{~mm}$ in length and $10 \mathrm{~mm}$ in thickness, fins height varies from 5 to $20 \mathrm{~mm}$, fin thickness varies from 1 to $5 \mathrm{~mm}$ and number of fins is 8 with a constant heat load of $20 \mathrm{~W}$ applied at the bottom of sink base and surrounding air temperature is taken at $27^{\circ} \mathrm{C}$. Similar geometries are also modeled in vertical orientation of sink base.

\subsection{Assumptions:}

1. Steady and laminar and three dimensional air flow

2. Air density was calculated by treating air as an ideal gas.

3. Apart from density, the properties of the fluid were independent of temperature with negligible radiation effect.

2.2. Governing equations [6]:

The continuity equation

$\left(\frac{\partial(\rho u)}{\partial x}+\frac{\partial(\rho v)}{\partial y}+\frac{\partial(\rho w)}{\partial z}\right)=0$

The Momentum equation in $\mathrm{X}, \mathrm{Y}$ and $\mathrm{Z}$ directions is as follows

$$
\begin{aligned}
& \frac{u \partial(u)}{\partial x}+\frac{v \partial(u)}{\partial y}+\frac{w \partial(u)}{\partial z}=-\frac{1}{\rho} \frac{\partial p}{\partial x}+v \frac{\partial^{2} u}{\partial x^{2}}+v \frac{\partial^{2} u}{\partial y^{2}}+v \frac{\partial^{2} u}{\partial z^{2}} \\
& \frac{u \partial(v)}{\partial x}+\frac{v \partial(v)}{\partial y}+\frac{w \partial(v)}{\partial z}=-\frac{1}{\rho} \frac{\partial p}{\partial y}+v \frac{\partial^{2} v}{\partial x^{2}}+v \frac{\partial^{2} v}{\partial y^{2}}+v \frac{\partial^{2} v}{\partial z^{2}}+g \beta\left(T-T_{\infty}\right)
\end{aligned}
$$

$$
\frac{u \partial(w)}{\partial x}+\frac{v \partial(w)}{\partial y}+\frac{w \partial(w)}{\partial z}=-\frac{1}{\rho} \frac{\partial p}{\partial z}+v \frac{\partial^{2} w}{\partial x^{2}}+v \frac{\partial^{2} w}{\partial y^{2}}+v \frac{\partial^{2} w}{\partial z^{2}}
$$

Energy conservation equation is as follows:

For heat sink and its base plate:

$k\left(\frac{\partial^{2} T}{\partial x^{2}}+\frac{\partial^{2} T}{\partial y^{2}}+\frac{\partial^{2} T}{\partial z^{2}}\right)+Q=0$

For working fluid

$$
\frac{u \partial(T)}{\partial x}+\frac{v \partial(T)}{\partial y}+\frac{w \partial(T)}{\partial z}=\alpha\left(\frac{\partial^{2} T}{\partial x^{2}}+\frac{\partial^{2} T}{\partial y^{2}}+\frac{\partial^{2} T}{\partial z^{2}}\right)
$$


wherein $u$, vand $w$ represent $x, y$, and $z$ direction of velocity vector, $\rho$ is the fluid density, $P$ and $T$ are the fluid pressure and temperature, respectively, $v$ is the dynamic viscosity coefficient, $g$ is the gravitational acceleration, $\beta$ is the thermal expansion coefficient of the fluid, $T_{\infty}$ is the Ambient temperature, $C$ is the specific heat of the object, $k$ is the thermal conductivity of object, $Q$ is the power output of the heat source, and $\alpha$ is the thermal diffusivity.

\subsection{Methodology}

The Ansys16.0 (work bench) Icepack, a CFD tool box based on finite volume method was used to model and analyze the natural convection heat transfer in an enclosure with a constant heat load of $20 \mathrm{~W}$ at sink base. Total number of 72 different geometrical heat sinks were modeled by varying the orientation, inclinations of fin surfaces, thickness and height of fins with 37552 grid nodes for each geometry as shown in the Fig 2.

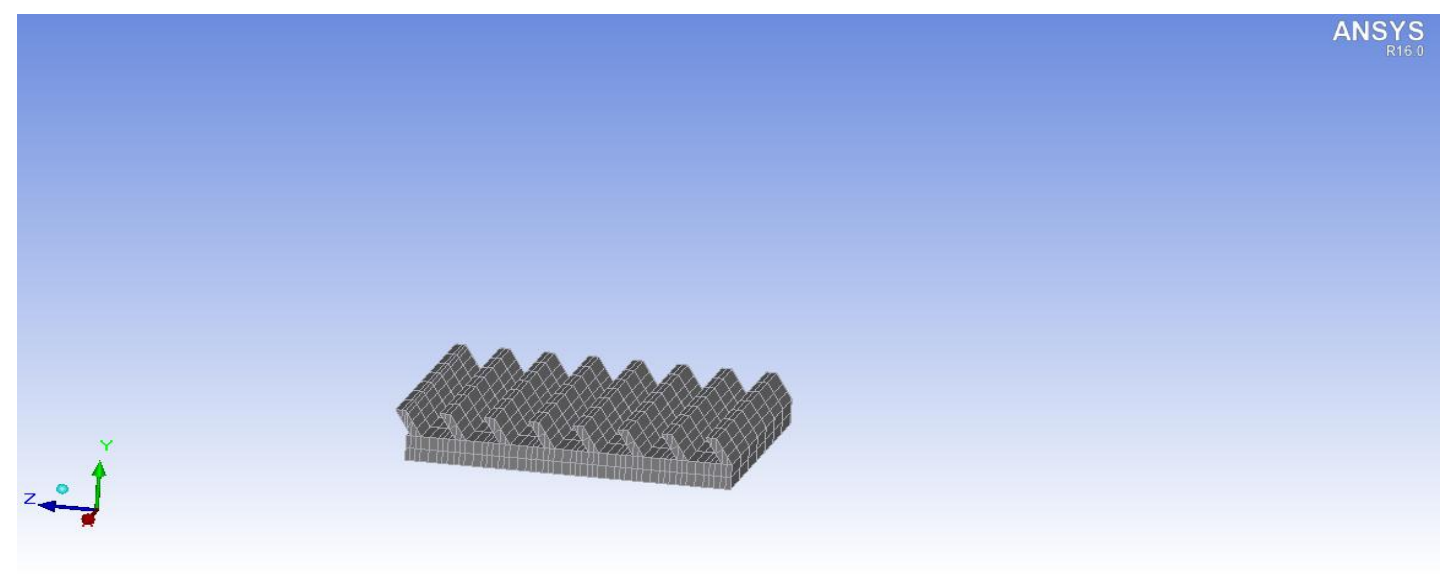

Fig. 2. Mesh Model

\section{RESULTS AND DISCUSSION}

The natural convection heat transfer simulation is carried on heat sinks with finned surface inclined to its base with a heat load of $20 \mathrm{~W}$. Fig 3 and 4 shows temperature contour of heat sink and velocity vector plots of surrounding air where the base plate is in horizontal position. Due to natural convection heat transfer, the air surrounding the sink gets heated and moves up due to force of buoyancy thereby carrying away the heat from the fins. Similar patterns are also observed in vertical orientation of base plate in Fig 5 and Fig 6 with a little enhancement in heat transfer coefficient.

\subsection{Effect of orientation}

Fig 7 shows the variation of heat transfer coefficient in both cases where base plate is placed in horizontal and vertical orientations. In this case the height of 8 fins is taken as $10 \mathrm{~mm}$ and thickness of $3 \mathrm{~mm}$ with a constant heat load of $20 \mathrm{~W}$. It has observed from the figure that as the angle of inclination increases, heat transfer coefficient starts to raise from $\theta=35^{\circ}$ to $40^{\circ}$, reaches peak and there by varies slightly in between $\theta=40^{\circ}$ to $75^{\circ}$, and decreases as the angle varies from $75^{\circ}$ to $85^{\circ}$ and again slight increase as the angle reaches to $90^{\circ}$. Same behavior was observed in both horizontal and vertical orientations whereas slight increase in the value of heat transfer coefficient in vertical orientation

\subsection{Effect of fin height}

Fig 8 and Fig 9 shows the heat transfer coefficient, $h$ and $\Delta T\left(\Delta T=T_{b}-T_{a}\right.$, Whereas $T_{b}$ is the base temperature of fin and $T_{a}$ is the surrounding air temperature) varies with height of fins changes from $5 \mathrm{~mm}$ to $20 \mathrm{~mm}$ and also with angle of inclinations of $\theta=35^{\circ}, 60^{\circ}$ and $90^{\circ}$ in horizontal orientation of base plate. The thickness of fin is $3 \mathrm{~mm}$ with a constant heat load of $20 \mathrm{~W}$ in all cases. It has been observed from the Fig 8 that heat transfer coefficient remains nearly constant with fin height for $\theta=90^{\circ}$ whereas for $\theta=35^{\circ}$ and $60^{\circ}$ it raises and lower with change of fin height. A large value of heat transfer coefficient is observed for $\theta=60^{\circ}$ at fin height of $12 \mathrm{~mm}$ is observed. Fig 9 shows the $\Delta \mathrm{T}$ decreases with increase in fin height as it signifies the decrease in thermal resistance.

\subsection{Effect of fin thickness}

Fig 10 and Fig 11 shows the heat transfer coefficient, $h$ and $\Delta T$ (where $\Delta T=T_{b}-T_{a}$ ) varies with thickness of fins varies from $1 \mathrm{~mm}$ to $5 \mathrm{~mm}$ and also with angle of inclinations of $\theta=35^{\circ}, 60^{\circ}$ and $90^{\circ}$ in horizontal orientation of base plate. The height of fin is $10 \mathrm{~mm}$ with a constant heat load of $20 \mathrm{~W}$ in all cases. From the Fig 10 it has been observed that for $\theta=35^{\circ}$, heat transfer coefficient increases with increase in thickness 1 to $2 \mathrm{~mm}$ and there by decreases with increase in thickness, whereas $\theta=60^{\circ}$ shows the better heat transfer coefficients with the increase in thickness compared with $\theta=90^{\circ}$. Fig. 11 shows the $\Delta \mathrm{T}$ changes with increasing thickness. For $\theta=35^{\circ}$ 
$\Delta \mathrm{T}$ decreases up to $3 \mathrm{~mm}$ thickness of fin thereby its starts to raise up to $5 \mathrm{~mm}$ of thickness, whereas for $\theta=60^{\circ}$ and $90^{\circ}$, whereas $\Delta \mathrm{T}$ remains nearly same with increase of thickness.

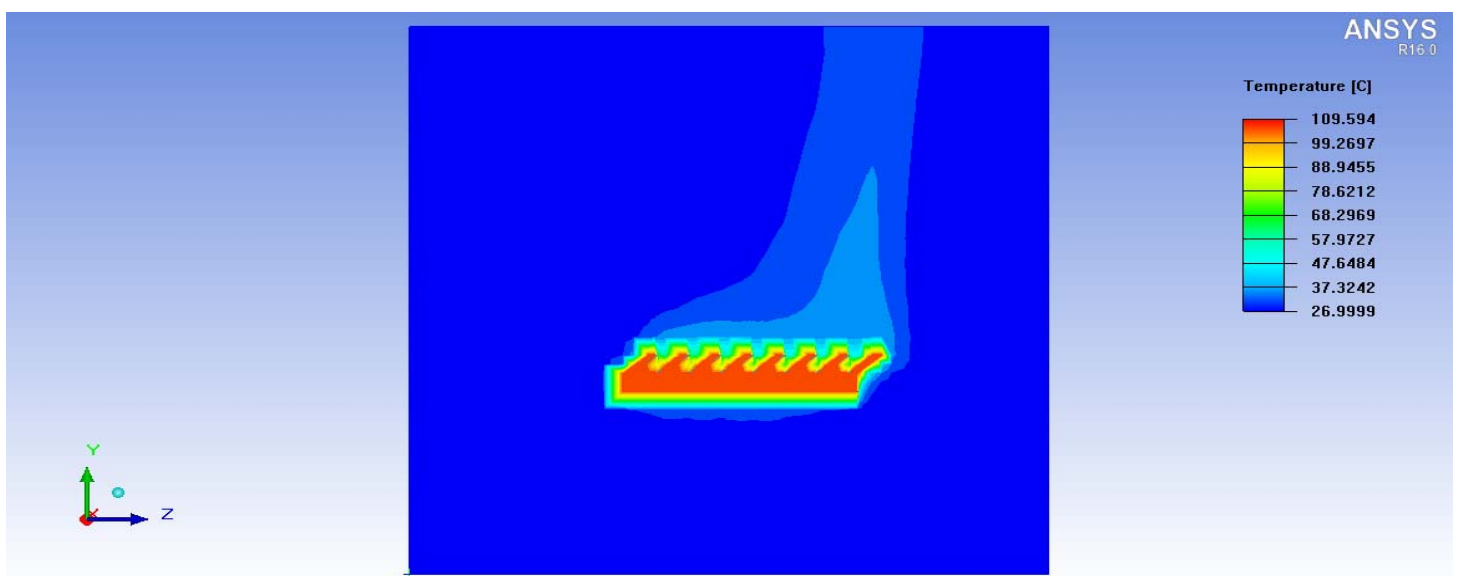

Fig. 3. Temperature contour of inclined fins at $\theta=40^{\circ}$ to its base surface in horizontal orientation of base plate

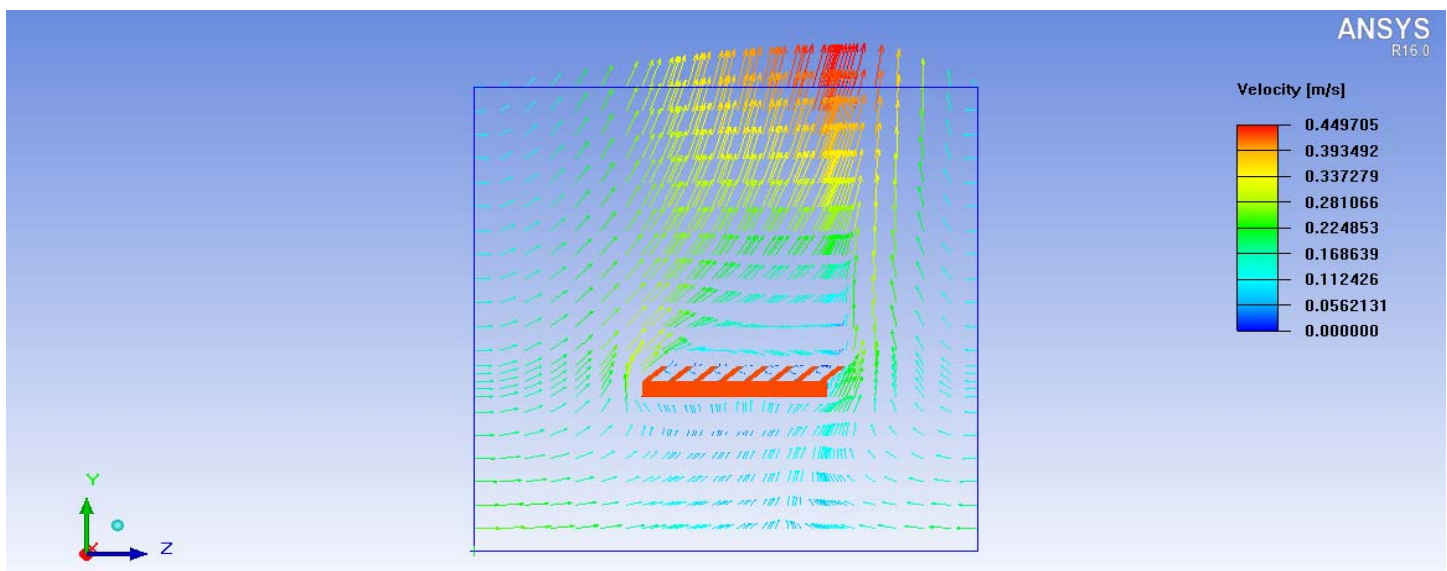

Fig.4. Velocity vector plot of inclined fins at $\theta=40^{\circ}$ to its base surface in horizontal orientation of base plate

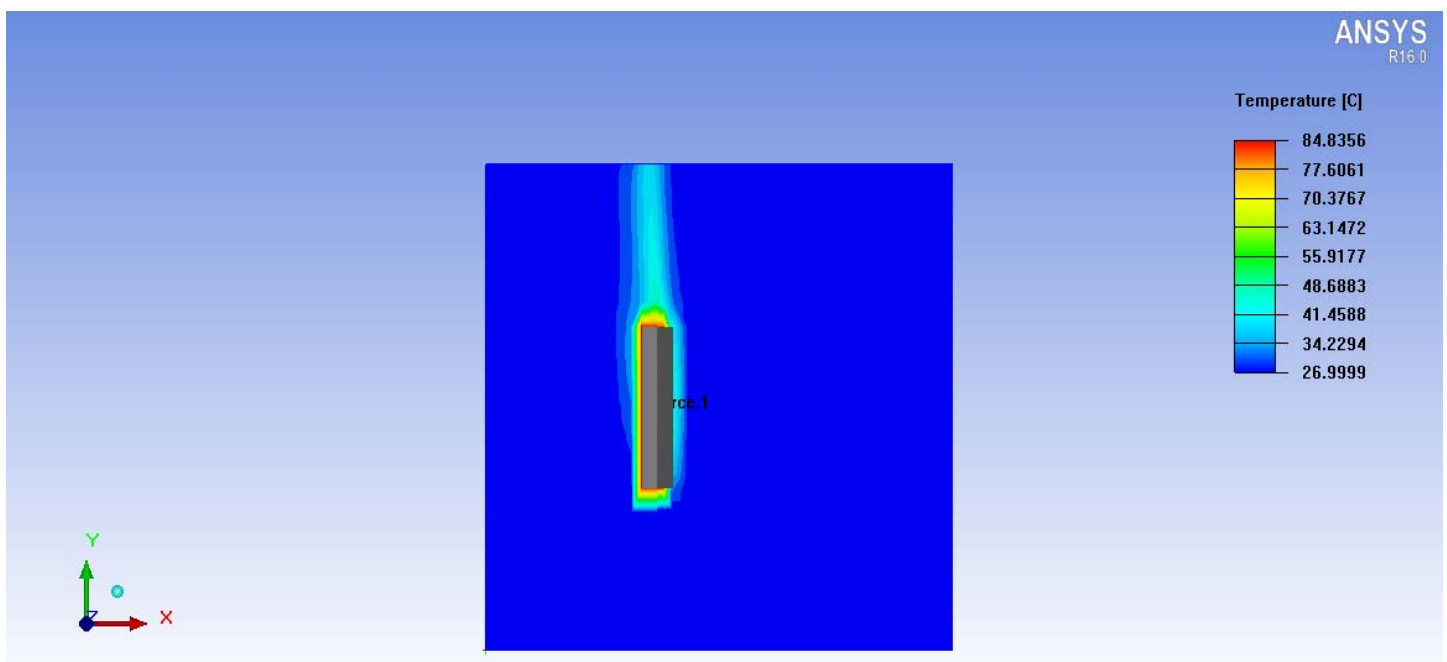

Fig. 5. Temperature contour of inclined fins at $\theta=40^{\circ}$ to its base surface in vertical orientation of base plate 


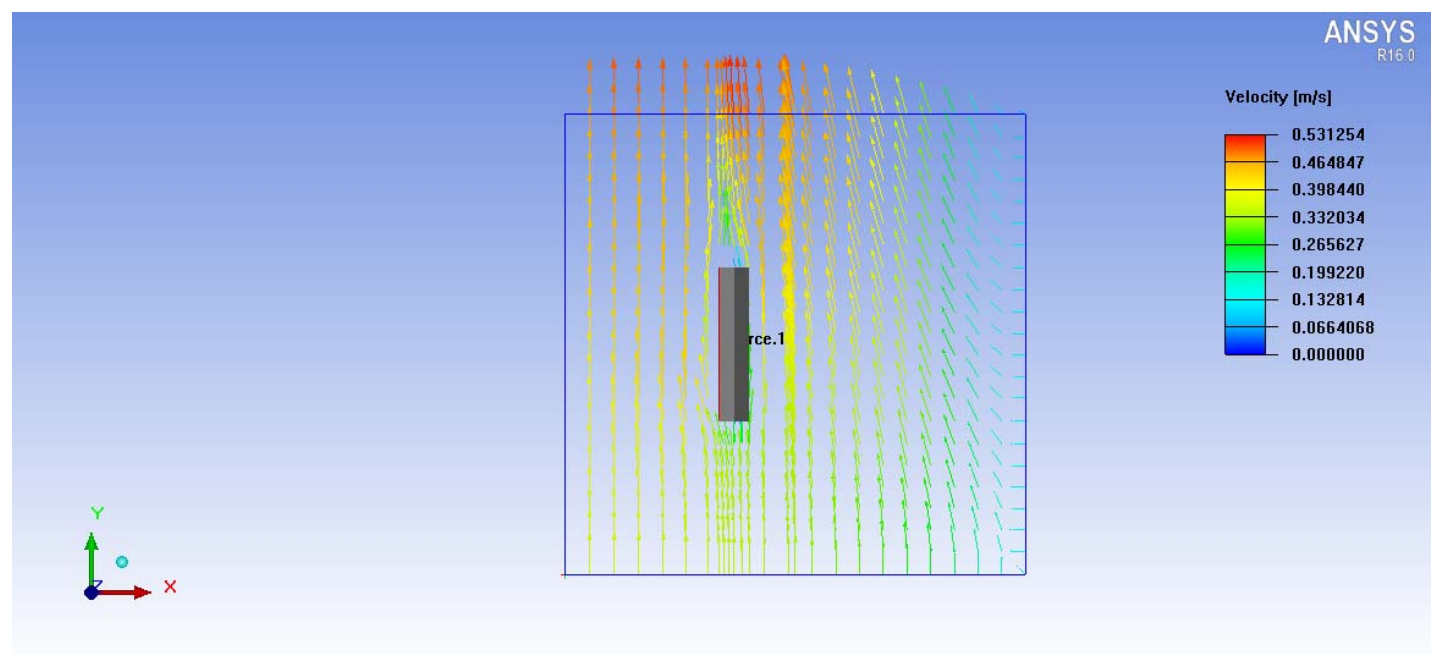

Fig.6. Velocity vector plot of inclined fins at $\theta=40^{\circ}$ to its base surface in vertical orientation of base plate

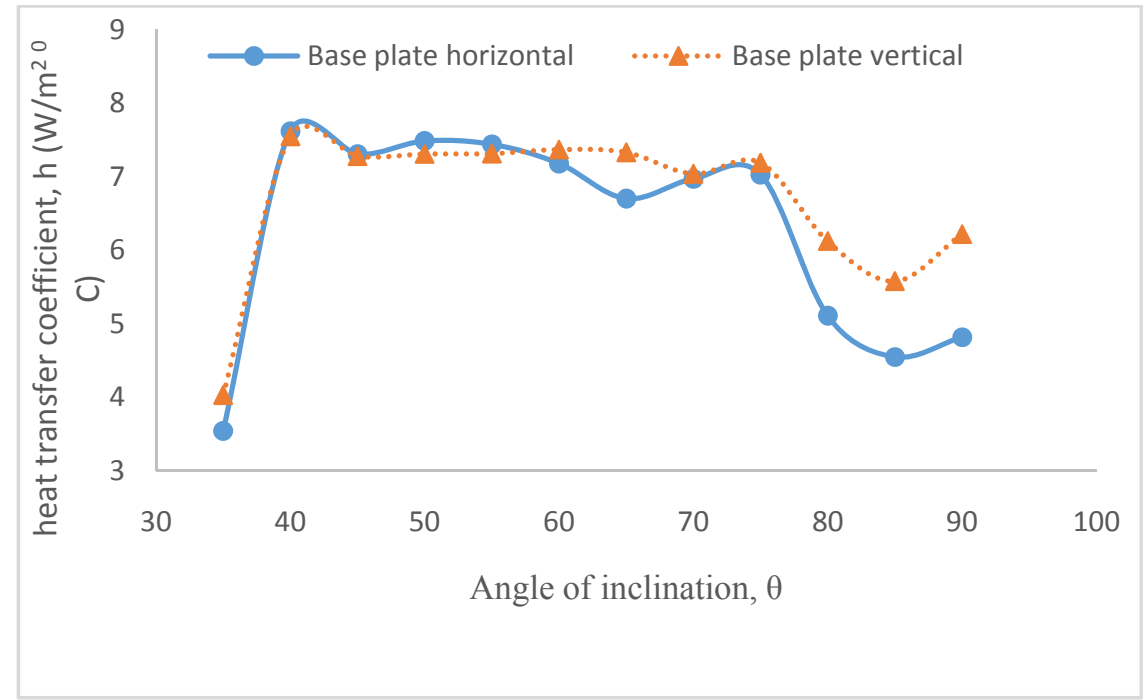

Fig. 7. Variation of heat transfer coefficient with angle of inclinations in both horizontal and vertical orientation of base plate

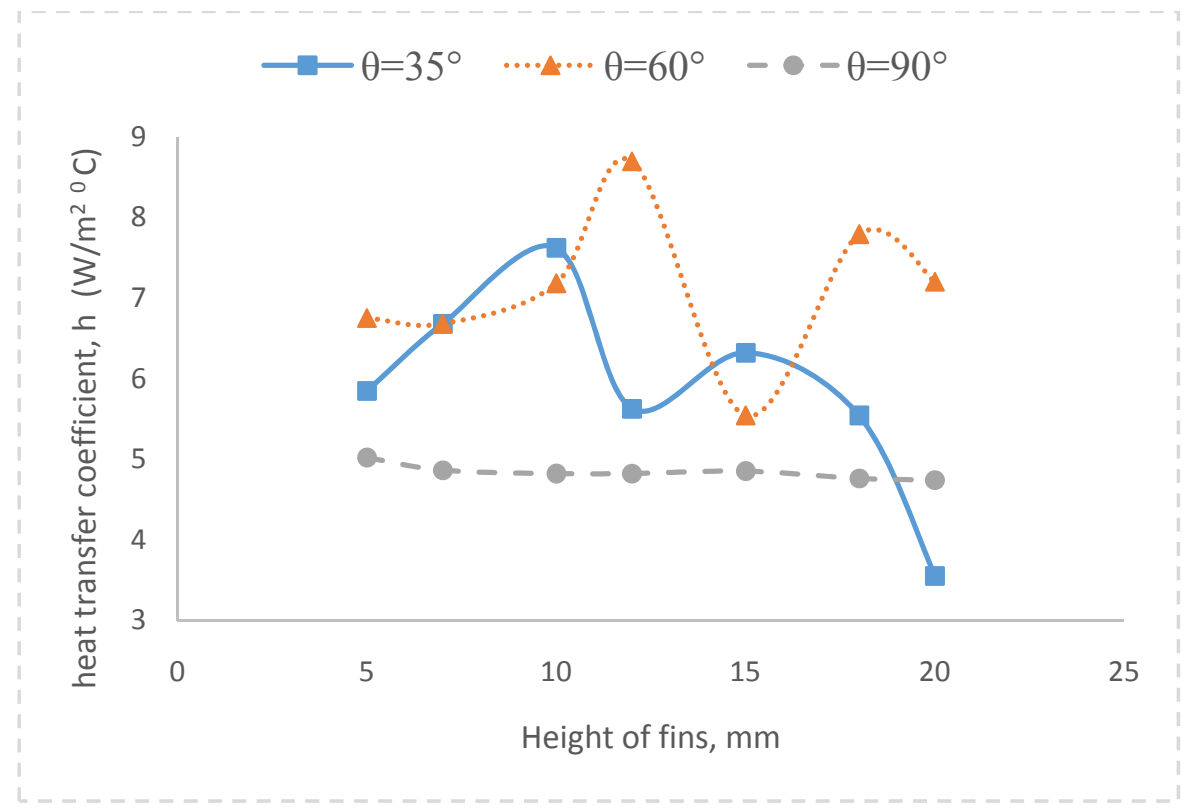

Fig. 8. Variation of convective heat transfer coefficient by varying height of fins in horizontal orientation of base plate. 


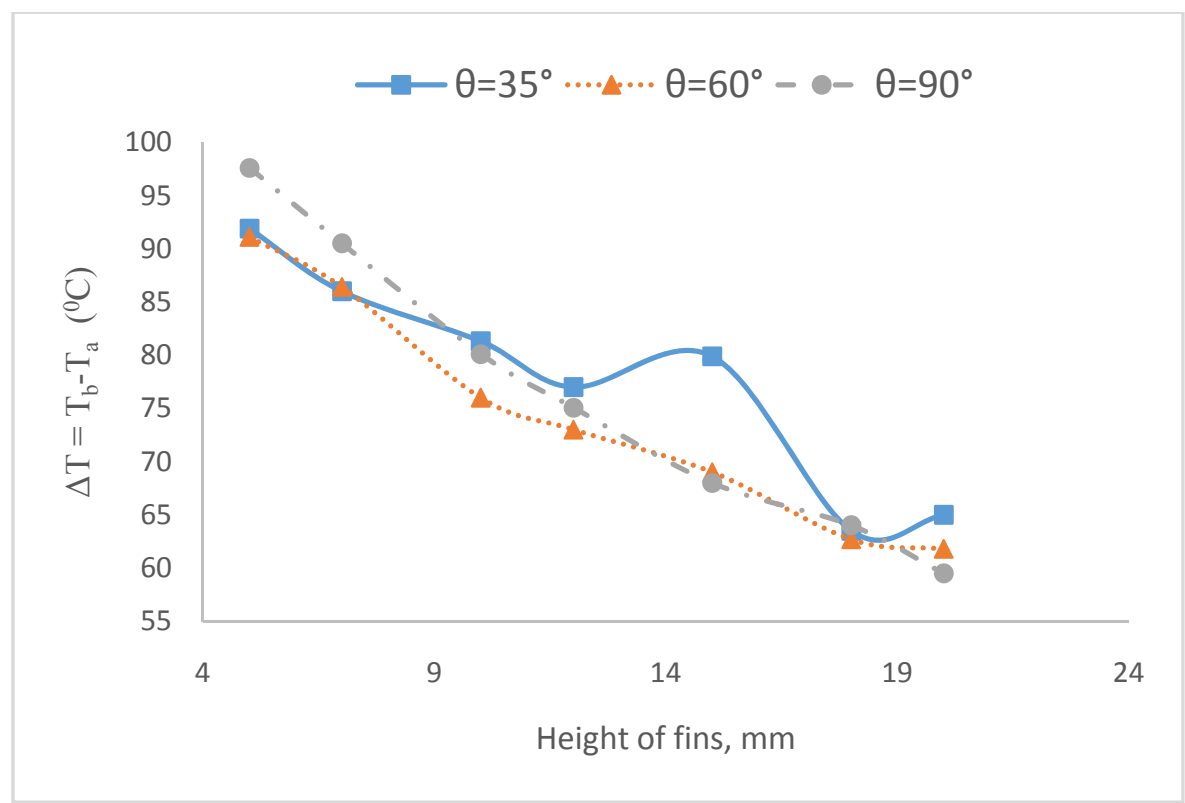

Fig. 9. Variation of $\Delta \mathrm{T}$ by varying height of fins in horizontal orientation of base plate.

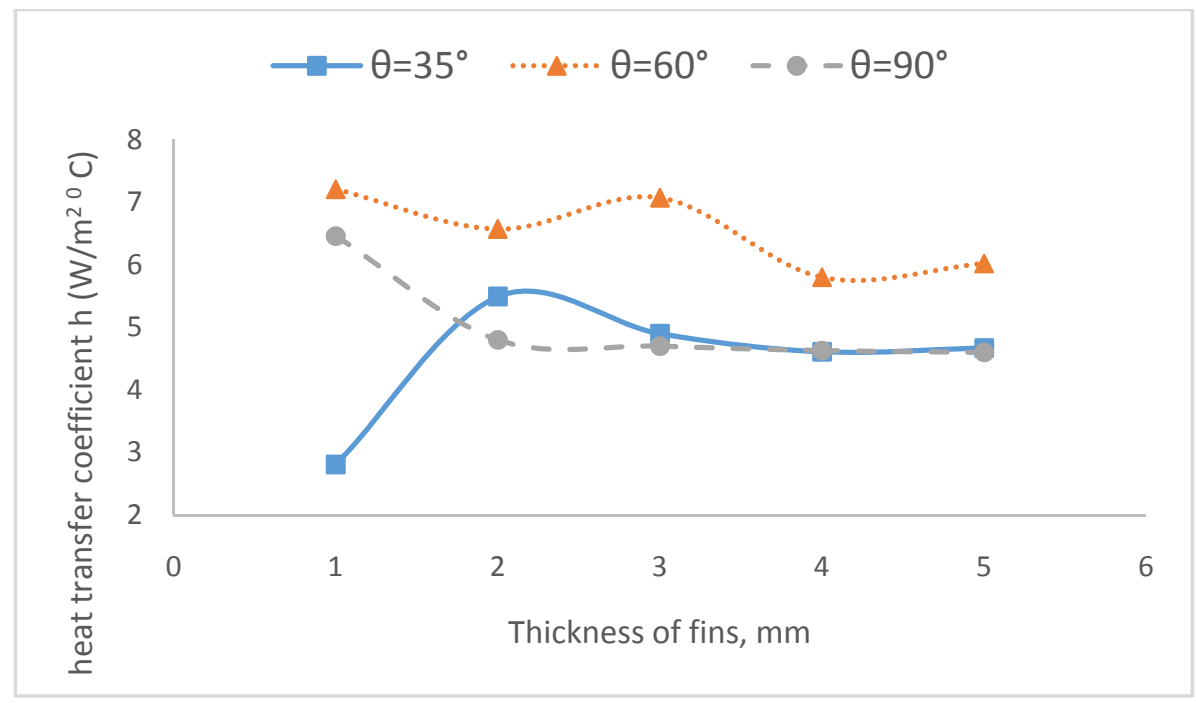

Fig. 10. Variation of convective heat transfer coefficient by varying thickness of fins at different fin angles in horizontal orientation of base plate.

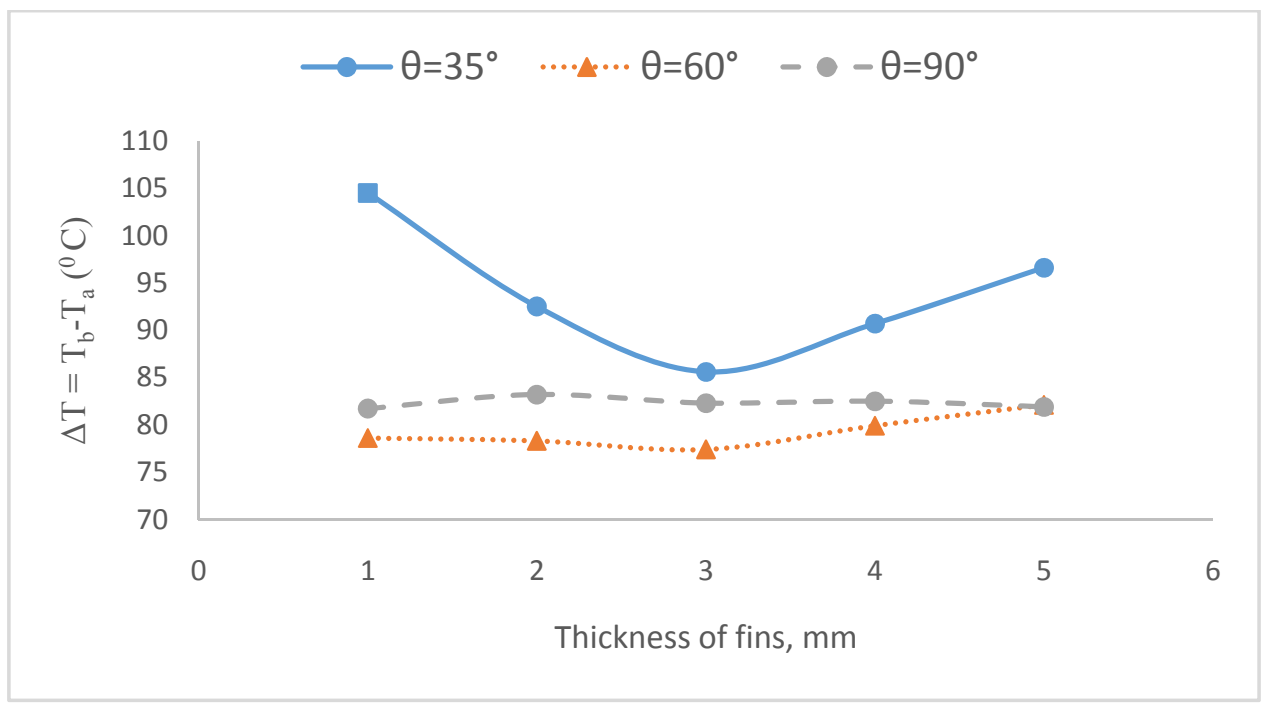

Fig. 11. Variation of $\Delta \mathrm{T}$ by varying thickness of fins at different fin angles in horizontal orientation of base plate. 


\section{IV.CONCLUSION}

A CFD simulation of natural convection heat transfer on fin surface inclined to base surface of heat sink was carried out with various angle of inclinations along with varying the thickness and height of fins with a constant heat load of $20 \mathrm{~W}$ applied at the bottom of the base plate of heat sink. The heat transfer coefficient in vertical orientation of base plate is observed to belittle enhanced than in horizontal orientation whereas finned surface inclination at an angle $60^{\circ}$ shows better convective heat transfer coefficient in both cases of varying height and thickness of fins and of lesser thermal resistance.

\section{REFERENCES}

[1] H. Yuncu, G. Anbar, "An experimental investigation on performance of rectangular fins on a horizontal base in free convection heat transfer" Heat and Mass Transfer 33 (1998) 507-514.

[2] Ilker Tari, Mehdi Mehrtash, "Natural convection heat transfer from horizontal and slightly inclined plate fin heat sinks"Applied Thermal Engineering 61 (2013) 728-736.

[3] S. V. Naidu, V. Dharma Rao, B. Govinda Rao, A. Sombabuand B. Sreenivasulu, "Natural convection heat transfer from fin arraysExperimental and theoretical study on effect of inclination of base on heat transfer" ARPN Journal of engineering and applied sciences $5(2010)$

[4] S. V. Kadbhane, D. D. Palande, "Experimental study of natural convective heat transfer from vertical rectangular fin array at different angle of inclination" International Journal of Current Engineering and Technology 5 (2016) 381-386.

[5] Welling JR, Wooldridge CB, "Free Convection Heat Transfer Coefficient from Rectangular Vertical Fins" J Heat Trans, Trans ASME, Series C 87: (1965) 439-444.

[6] Li-Ming Chu, Wei-Chin Chang, and Ting Hsuan Huang, "A Novel Heat Sink Design and Prototyping for LED Desk Lamps" Mathematical Problems in Engineering, Volume 2015, Article ID 765969, 8 pages.

[7] Gardner KA. Efficiency of extended surface. ASME J Heat Transfer, (1945)621-31.

[8] Patankar SV, "Numerical Heat Transfer and Fluid Flow," (1980) McGraw-Hill, New York.

\section{AUTHOR PROFILE}

Mr. Sk. Farooq, M. Tech (IIT Kharagpur) working as Assistant Professor from the last 5 years in the department of mechanical engineering at VFSTR University. 